\title{
Supporting health behaviour change in chronic obstructive pulmonary disease with telephone health-mentoring: insights from a qualitative study
}

Julia A E Walters ${ }^{1 *}$, Helen Cameron-Tucker ${ }^{1}$, Helen Courtney-Pratt ${ }^{2}$, Mark Nelson ${ }^{3}$, Andrew Robinson ${ }^{2}$, Jenn Scott ${ }^{4}$, Paul Turner ${ }^{5}$, E Haydn Walters ${ }^{1}$ and Richard Wood-Baker ${ }^{1}$

\begin{abstract}
Background: Adoption and maintenance of healthy behaviours is pivotal to chronic disease self-management as this influences disease progression and impact. This qualitative study investigated health behaviour changes adopted by participants with moderate or severe chronic obstructive pulmonary disease (COPD) recruited to a randomised controlled study of telephone-delivered health-mentoring.
\end{abstract}

Methods: Community nurses trained as health-mentors used a patient-centred approach with COPD patients recruited in general practice to facilitate behaviour change, using a framework of health behaviours; 'SNAPPS' Smoking, Nutrition, Alcohol, Physical activity, Psychosocial well-being, and Symptom management, through regular phone calls over 12 months. Semi-structured interviews in a purposive sample sought feedback on mentoring and behaviour changes adopted. Interviews were analysed using iterative thematic and interpretative content approaches by two investigators.

Results: Of 90 participants allocated to health-mentoring, 65 (72\%) were invited for interview at 12-month follow up. The 44 interviewees, $75 \%$ with moderate COPD, had a median of 13 mentor contacts over 12 months, range 5-20. Interviewed participants ( $n=44,55 \%$ male, $43 \%$ current smokers, $75 \%$ moderate COPD) were representative of the total group with a mean age 65 years while $82 \%$ had at least one additional co-morbid chronic condition. Telephone delivery was highly acceptable and enabled good rapport. Participants rated 'being listened to by a caring health professional' as very valuable. Three participant groups were identified by attitude to health behaviour change: 14 (32\%) actively making changes; 18 (41\%) open to and making some changes and 12 (27\%) more resistant to change. COPD severity or current smoking status was not related to group category. Mentoring increased awareness of COPD effects, helping develop and personalise behaviour change strategies, even by those not actively making changes. Physical activity was targeted by 43 (98\%) participants and smoking by 14 (74\%) current smokers with 21\% reporting quitting. Motivation to maintain changes was increased by mentor support.

Conclusions: Telephone delivery of health-mentoring is feasible and acceptable to people with COPD in primary care. Health behaviours targeted by this population, mostly with moderate disease, were mainly physical activity and smoking reduction or cessation. Health-mentoring increased motivation and assisted people to develop strategies for making and sustaining beneficial change.

Trial registration: ACTR12608000112368

Keywords: Health-mentoring, Behaviour change, Primary care, Chronic obstructive pulmonary disease, Physical activity, Smoking

\footnotetext{
* Correspondence: Julia.Walters@utas.edu.au

'University of Tasmania, MS1 UTAS, Private Bag 23, Hobart, TAS 7000,

Australia

Full list of author information is available at the end of the article
}

\section{Biomed Central}

(c) 2012 Walters et al.; licensee BioMed Central Ltd. This is an Open Access article distributed under the terms of the Creative Commons Attribution License (http://creativecommons.org/licenses/by/2.0), which permits unrestricted use, distribution, and reproduction in any medium, provided the original work is properly cited. 


\section{Background}

Chronic Obstructive Pulmonary Disease (COPD), a major cause of morbidity worldwide [1] is a common chronic condition seen in Australian general practice. The prevalence is $13.5 \%$ in primary care [2], with management occurring at a rate of 8 per 1000 general practitioner (GP) encounters [3]. Despite a high rate of misdiagnosis $(30 \%)$ and delayed diagnosis [4,5], COPD management is often reactive [6] and COPD seen as subsidiary to the patients' other chronic conditions [6,7]. However, the financial cost of COPD is very high for the health system and there is a large impact on individuals, with loss of productive healthy years of life [8]. A number of management approaches alongside conventional medical interventions have been deployed to try to reduce the COPD disease burden, such as patient-directed self-management interventions [9] including education or behavioural support [10].

Interventions to support self-management, $[9,11]$ including adoption of health behaviours meeting guidelines for good health [12], could reduce the impact and slow deterioration in COPD. However, patients often have poor understanding of the nature of the disease and frequently fail to monitor symptoms [13] or make lifestyle changes that could have positive benefits [14]. They may experience marked impairment of quality of life impacting on activity, symptoms and participation in daily life [15]. They may also report poor knowledge about how to prevent worsening [16] and express confusion and even denial about smoking as the main causal factor [17].

In addition to smoking there are high rates of other preventable risk factors for disease in the Australian population, [18] including risky alcohol consumption, poor nutrition, and physical inactivity, which are targets for improvement highlighted in the recent national preventive health strategy [19]. However, there are challenges to achieving behaviour change around risk factors to improve long-term outcomes in COPD [20]. Without assistance to develop strategies for change, patient education and knowledge alone are not effective in improving health status [10] [21]. This raises issues over the traditional approach to lifestyle counseling in primary care which is didactic rather than patient-oriented [22].

Self-management support interventions may be designed to address one or two specific health behaviours through education and coaching. Previous studies have addressed physical activity and diet in type 2 diabetes, hypertension in a primary care population [23] and seven specific coronary risk factors in established cardiac disease [24]. However, as the majority of patients with chronic disease in primary care have multiple comorbidities, each with its own management priorities, an individual may benefit from behaviour change for multiple risks factors [25] and little is known about health behaviours that patients with chronic conditions themselves chose to address.

The qualitative study reported in this paper used interviews to investigate health behaviour changes adopted by people with moderate or severe COPD during a randomised controlled study of telephone-delivered healthmentoring to support self-management in primary care.

\section{Methods}

\section{Selection of participants for interview}

Participants were recruited from the telephone-delivered health-mentoring arm of a 12-month cluster randomised study undertaken in 31 general practices for patients with moderate or severe COPD. The study was approved by the Tasmanian Human Research Ethics Committee (H0009777) and was conducted between 2008 and 2010. Participants gave written informed consent and all those attending a 12-month follow up visit were invited to take part in the qualitative study. A purposive sample of those who agreed completed a semi-structured telephone interview of approximately 45 minutes duration. The sample selection sought to reflect a range of locations and number of health-mentor contacts, and study participants' distribution by gender, smoking status, employment and educational level. Recruitment ceased after it appeared that the attributes of interviewees reflected our desired range and that we had sufficient to achieve content issue saturation.

\section{Health-mentoring}

Nurses working in primary care as community or practice nurses were trained as health-mentors to assist people with chronic diseases to identify personal goals and health-related action plans directed to goal achievement. The two-day training programme was grounded in behavioural psychological theory and included: motivational interviewing skills; goal setting; action planning and problem solving; self-management support theory and practice; and a COPD-specific clinical management module [4]. Health-mentoring used a patient-centred approach to facilitate behaviour adoption or maintenance in the 'SNAPPS' framework of health behaviours; Smoking, Nutrition, Alcohol, Physical activity [26], Psychosocial well-being, and Symptom management. The intended mentoring schedule included 16 telephone calls, whose frequency varied from weekly initially then tapering to two monthly over 12 months.

\section{Data collection, outcomes and analysis}

Participants' demographic, anthropometric and comorbidity data were collected and questionnaires were administered to assess symptoms and health status via the Medical Research Council (MRC) scale for functional 
dyspnoea [27], and the St George's Respiratory Questionnaire (SGRQ) for health related quality of life at baseline.

Qualitative data were collected by a trained, experienced, independent researcher (KN) during a semistructured interview completed within four weeks after 12-month follow up and sought feedback on the healthmentoring process and health behaviour adoption or maintenance. Interviews were audiotaped and transcribed verbatim and two researchers performed initial analysis using an iterative thematic approach [28]. After initial reading of transcripts, coding was performed independently by two researchers (JW and DW) who sought themes relating to health behaviour change and mentoring [29]. Emergent themes were subsequently discussed with other authors (HCT, HCP) and were examined using NVivo in relation to interviewees' demographic status, disease severity and disease impacts. Interpretative content analysis was subsequently used to quantify interviewees' health behaviour changes [28]. Findings are illustrated with quotes from participants whose age, smoking status and COPD severity at the start of the study are shown in parentheses.

\section{Results}

Ninety study participants were allocated to the healthmentoring intervention, of whom 65 (72\%) were invited for interview when attending 12-month follow up (11 withdrew before commencing the allocated intervention, 12 withdrew later without follow up, 2 died). The 44 interviewees, 33 with moderate COPD and with 11 severe COPD had a median of 13 mentor contacts over 12 months, range 5-20. Demographics, and disease impacts in the interviewees were comparable to the whole group of mentored participants, although the proportion of participants with COPD graded as moderate was greater in the interviewed (75\%) compared to the non-interviewed (50\%) participants (Table 1). COPD was the only chronic disease reported by $18 \%$ of interviewees, 39\% had one other chronic disease and 34\% had two or three other chronic conditions.

\section{Impact of health-mentoring on making health behaviour changes}

The experience of participating in telephone healthmentoring was for most participants, a valuable one. They believed that mentors helped them to identify goals, activities and strategies that assisted them with management of their COPD and their general wellbeing. The majority of participants indicated a change in health behaviours as a consequence of their participation in the telephone mentoring with $14(32 \%)$ actively making health behaviour changes, 18 (41\%) showing openness to change and making some small change(s), and 12 (27\%) appearing somewhat more resistant to making changes.
Table 1 Characteristics of interviewed participants $(n=44)$ and non-interviewed participants $(n=46)$ in a study of telephone delivered health mentoring in COPD

\begin{tabular}{|c|c|c|c|c|}
\hline & \multicolumn{2}{|c|}{$\begin{array}{l}\text { Interviewed } \\
n=44\end{array}$} & \multicolumn{2}{|c|}{$\begin{array}{l}\text { No interview } \\
n=46\end{array}$} \\
\hline & Mean & SD & Mean & SD \\
\hline Age (years) & 65.2 & 7.3 & 64.3 & 8.5 \\
\hline Functional dyspnoea (MRC 1-5) ${ }^{1}$ & 2.6 & 1.1 & 2.9 & 1.3 \\
\hline \multirow{2}{*}{$\begin{array}{l}\text { Health related quality of life SGRQ } \\
(0-100 \text { worst })^{2}\end{array}$} & 41.3 & 21.1 & 42.6 & 18.4 \\
\hline & $\mathbf{n}$ & $\%$ & $\mathbf{n}$ & $\%$ \\
\hline Current smoker & 21 & 48 & 23 & 50 \\
\hline Male & 24 & 55 & 24 & 52 \\
\hline \multicolumn{5}{|l|}{ COPD severity* } \\
\hline FEV1 $50-80 \%$ predicted $=$ Moderate & 33 & 75 & 23 & 50 \\
\hline FEV1 $30-50 \%$ predicted $=$ Severe & 11 & 25 & 23 & 50 \\
\hline Living alone & 18 & 41 & 18 & 39 \\
\hline Overweight or obese ${ }^{3}$ & 30 & 68 & 29 & 64 \\
\hline Employed currently & 11 & 25 & 8 & 17 \\
\hline \multicolumn{5}{|l|}{ Education level } \\
\hline Primary & 3 & 7 & 8 & 17 \\
\hline Year 7-10 & 25 & 57 & 24 & 52 \\
\hline Year 11 or 12 & 6 & 14 & 6 & 13 \\
\hline Certificate/diploma & 6 & 14 & 5 & 11 \\
\hline University degree & 4 & 9 & 3 & 7 \\
\hline Previous self-management education & 3 & 7 & 6 & 13 \\
\hline
\end{tabular}

Footnotes: ${ }^{1}$ MRC $=$ Medical Research Council scale; ${ }^{2}$ SGRQ $=$ St George's Respiratory Questionnaire; ${ }^{3}$ Overweight or obese $=\mathrm{BMl} \geq 25 \mathrm{~kg} / \mathrm{m}^{2} .{ }^{*} \mathrm{Chi}^{2}$ $\mathrm{p}<0.05$.

Behaviour change responses were not related to the participants' severity of COPD. Based on analysis of interview transcripts, the most frequent changes in health behaviours occurred in relation to physical activity (43 participants, 98\%), reducing smoking (14 participants, $74 \%$ current smokers) or achieving smoking cessation (21\% of current smokers reported having quit at interview), nutrition (10 participants, 23\%) and symptom management (8 participants, 18\%).

\section{Changing smoking behaviour}

Participants who were still actively smoking during the course of the programme reported that mentoring had changed the way they thought about their smoking, which in turn led to changes in their smoking habits:

"As I started saying it was the philosophy behind why one habitually does something, no matter what. The purpose behind it, the reason for it, etcetera, etcetera. And she [the mentor] always brought me back round [in the discussion] to where I was at that time. And every time she rang me I had taken a step. And it was 
really good to discuss with her. And she knew from the word go, because I made it quite clear, do not expect miracles... But you know, suddenly because, because our call was important... I'd find myself thinking, you know, suddenly something would strike me and oh, I will leave those [the packet of cigarettes] inside while I go and plough the field. And yeah, I'm not taking them in the car today... So she made me very aware of what I was doing, instead of doing it automatically." (\#4045, female, age 62, smoker, moderate COPD)

Another participant talked about how he had managed to quit smoking during the course of the program, and how the support of the mentor had helped achieve this when he said "They were sort of complimenting me on what I was doing. Or trying to do" (\#4041, male, age 66, smoker, moderate COPD)

Mentor support was seen as different from, and more effective, than family advice:

"[the mentor] somebody different to talk to, to open up to. Um, somebody more understanding ah, whereas at home all I cop is 'just give the bloody things up'. You know, 'it's simple' all that sort of thing. Yeah, it was easier to talk to [the mentor] than it is to talk to my wife about it... And the end result will be that I will give up the cigarettes. I haven't done so yet, but I will. What I did do was reduce the number I was taking quite significantly.” (\#4071, male, age 59, smoker, moderate COPD)

The opportunity to discuss personal health issues with someone outside the family circle was valued:

"Being able to talk to somebody outside the family about what was wrong with you. That's always handy, because the family are a bit close and you know, they have to live with it, which makes it very difficult for them." (\#4049, female, age 64, smoker, severe COPD)

Considering simple strategies with the health-mentor gave participants the knowledge they needed to make changes, "She said 'Well, why don't you leave them at home?' I said 'Well I never thought of that!' (\#4559, male, age 71, smoker, moderate COPD). Sometimes participants believed that they had been able to make changes to their smoking because of the strategies their mentor had provided to cut down or give up:

"And on the smoking side, it [mentoring] was excellent. She [my mentor] gave me the ways and means of trying to either cut down [my smoking] dramatically, which I did do..." (\#4063, female, age 68, smoker, moderate COPD)

\section{Changing physical activity}

A focus on exercise adoption or maintenance was also something that most participants discussed, and this health behaviour change was demonstrated through participation in this program.

"... I suppose I was more aware of what I must do for my lungs. Like the exercising and that sort of thing. So that did make me focus a little bit on that

[exercising], which was good because that is something that I can help... But she was a great moral support.

And yes, I was able to sort of focus and to know what I needed to do for the lungs" (\#4600, female, age 67, exsmoker, moderate COPD)

The experience of participating in telephone healthmentoring made participants reassess some of the activities of daily living which they had taken for granted, such as exercise, which in turn led to behaviour change. One participant talked about how the health-mentoring had made them think about how to change their normal routines to include more exercise, leading to achieving more exercise by "just giving it a try" (\#4041, male, age 66, smoker, moderate COPD).

"Parking in say one spot, and going to the post office and bakery and the chemist from the one spot instead of going to the chemist and getting in the car and driving down to the bakery and the post office" (\#4041, male, age 66, smoker, moderate COPD)

Another participant indicated a similar sentiment:

"I didn't think about doing these things [increasing my exercise] ... but she said 'What about going for a walk?'.. and you know, [now] I have a walk every day kind of thing. . once I started on it, it was alright"

(\#4559, male, age 71, smoker, moderate COPD)

\section{Motivational elements of health-mentoring}

Participants identified several ways that telephone healthmentoring supported them in making health behaviour changes. For some participants, health-mentoring provided the regular reminder they needed to instigate changes:

"Most of the things. . were pretty obvious. I just needed that little bit of a prompt to get me to do them sort of thing”. (\#4556, female, age 65, exsmoker, moderate COPD)

Participating in health-mentoring also helped to reinforce existing health behaviours by raising and refocusing participant awareness on the management of their COPD, and what positive health behaviours they 
could be doing, as distinct from just providing information:

\section{"No, not the knowledge, [it was] not the knowledge, but strategies, in terms of... just sort of being consciously aware [of the need to change my behaviours], rather than sort of automatically doing something. And [now] I'll think to myself consciously... do this... do that. So she [my mentor] was instrumental in that" (\#4045, female, age 62, smoker, moderate COPD) Another participant stated}

"It [the health-mentoring] made me go back to thinking about myself and watching [what I did]. You know, being aware of what I was doing" (\#4600, female, age 67, exsmoker, moderate COPD).

The experience of telephone health-mentoring created a partnership between the participant and the mentor, which encouraged participants to commence, strengthen or continue positive health behaviours. In some cases the participant felt that they had a responsibility to their health-mentor to try and achieve some of the goals they had discussed. Additionally, just the knowledge that the mentor would be calling was also sometimes enough for participants to make positive health choices or change health behaviours. For example, one participant stated:

'Well mentally to know that I am getting a phone call every now and again was a big help' (\#4088, female, age 68, exsmoker, moderate COPD).

Another discussed the feeling of accountability she felt as a participant in the program and how this helped motivate her to increase her physical activity:

"Oh basically it [working with the health-mentor] was just support and motivation. Like if I knew she was ringing I would think I better go and do a couple of walks, because she is going to bloody ask me" (\#4510, female, age 60, exsmoker, severe COPD)

Participants persisted with behaviour changes through health-mentors' encouragement and fostering problem solving

"Well when [the health-mentor] would ring again, I'd say to [the health-mentor]... 'I didn't quite get this' and [the health-mentor] would say 'well you know, think about types of things why and what sort of things and things like that' and then I would go that step further and look that step further" (\#4037, female, age 45, exsmoker, moderate COPD)
Participants with severe COPD reported the need for perseverance to overcome difficulties in making behaviour changes.

"Well I push myself all the time. I wont let it get on top of me, because it can be very easy to do that. Um, throw in the towel if you like... I go outside and I force myself to do things. I got to push my body along as much as I can. I still do quite a bit of work. It's slow, but I still do it” (\#4125, male, age 70, exsmoker, severe COPD)

\section{Discussion}

Telephone health-mentoring delivered by trained nurses working in a community setting was favourably received by people with moderate or severe COPD, of whom the majority had other co-morbid chronic conditions. They reported that it assisted them to focus on and modify or adopt health behaviours. They most frequently targeted physical activity and stopping smoking. Healthmentoring increased mentees' motivation, helped them to develop strategies for change and to sustain those behavioural changes.

Traditionally self-management support interventions, delivered by telephone, are targeted at only one or two specific health behaviours, such as physical activity in sedentary people at increased risk of type 2 diabetes [30], or physical activity and diet in type 2 diabetes and hypertension [31]. The target health behaviours are usually determined by the perceived importance to the health professional for disease causation in the population being studied. In clinical practice, primary care health professionals show considerable variation in assessing lifestyle behavioural risk factors [32], but again treatment choices are generally influenced by the health professionals' beliefs and attitudes, and also by geographic location, consultation context and the patient's socio-economic status. Surprisingly, there has been little published and there is little relevant information on the patient's perspective on choice of target health behaviours. In contrast, health-mentoring delivers individual self-management support that is patient-focused. The health-mentor training given to community nurses in this study deliberately focused on a range of health behaviours linked to known risk factors for chronic diseases [26] but a key message taught was to facilitate individual participant choice.

Smoking is the principal risk factor for development of COPD and thus might be predicted as a target for behaviour change in people suffering from the condition. However, some smokers construct a narrative in which they do not accept smoking to be the main reason for development of their own COPD [17] and smoking prevalence is actually greater among people with more 
severe disease [33]. Of note in this study, a majority of smokers reported changes in smoking behaviour, and although reduction of smoking rather than cessation sometimes resulted, the attitude and motivation of most smokers demonstrated change. This is important because the study of Williams et al. [34] has shown that support to make a clear and autonomous decision about whether or not to make a quit attempt increases cessation in smokers not otherwise motivated to quit - such a decision was found to be a critical factor in enhancing their motivation.

The choice of physical activity as target for change by almost all participants reflects the impact of COPD and impaired functional capacity, compared to healthy elderly people [35]. This is important because increased physical activity is likely to be beneficial for individuals with COPD, improving their quality of life [36] and reducing the decline in their lung function [37].

Another study using a comprehensive face-to-face hospital based self-management education program in COPD [10] found that in addition to physical activity, improved nutrition and managing deteriorating symptoms were behaviours addressed by some patients. In that study participants had very severe COPD and behaviour change was reinforced with regular follow-up telephone calls, but only around a quarter still smoked [21]. In our study, participants were recruited in primary care with less severe COPD, nearly half being current smokers whose future course would benefit greatly from quitting.

Participants interviewed in our study were representative of the whole health-mentored group and reflected the typical primary care COPD population in Australia in having multiple chronic disease comorbidities [25]. Thus the results are likely to be generalisable to the whole COPD primary care population.

\section{Conclusions}

Engaging people in health behaviour change is recognized as a high priority in primary care [19]. However, achieving and maintaining change is difficult. This may be especially true in COPD, with patients experiencing helplessness that is reinforced by repeated bad experiences [38]. The qualitative results from this study of health-mentoring have demonstrated that supporting participants' autonomy in health behaviour adoption or maintenance was possible, and can be effective in increasing their self-motivation for change [39]. It was apparent in our study that health behaviours targeted for change were appropriate to prevention and improving quality of life in COPD while being directed by participant preference. This is encouraging for direct patient coaching telephone services that have recently become available in parts of Australia (https://www.gethealthynsw. com.au/) for prevention of chronic disease in adults at risk of developing chronic diseases from some lifestyle risk factors such as diet and inadequate physical activity. However a notable omission from the target current specified risk factors is smoking cessation, which was the choice for action by the majority of current smokers in this study.

\section{Abbreviations}

COPD: Chronic Obstructive Pulmonary Disease; MRC: Medical Research Council; SD: Standard deviation; SGRQ: St George's Respiratory Questionnaire; FEV1: Forced expiratory volume in 1 second.

\section{Competing interests}

The authors declare that they have no competing interests.

\section{Acknowledgements}

We thank Kym Nutting (KN) who conducted most of the semi-structured interviews with participants, Karen Herne who transcribed all interviews and Danielle Williamson (DW) who conducted initial analyses of interview transcripts. This work was supported by a National Health and Medical Research Council project grant, a Royal Hobart Hospital Research Foundation Research Grant and an Institutional Research Grant from the University of Tasmania. J. Walters was supported by an Australian Lung Foundation/ Boehringer Ingelheim COPD award. Importantly, we thank the nurses, practices and patients who participated in the study.

\section{Author details}

'University of Tasmania, MS1 UTAS, Private Bag 23, Hobart, TAS 7000, Australia. ${ }^{2}$ University of Tasmania, Private Bag 135, Hobart, TAS 7000 Australia. ${ }^{3}$ Menzies Research Institute Tasmania, University of Tasmania, MS1 UTAS, Private Bag 23, Hobart, TAS 7000, Australia. ${ }^{4}$ University of Tasmania, Private Bag 30, Hobart, TAS 7000, Australia. ${ }^{5}$ University of Tasmania, Private Bag 100, Hobart, TAS 7000, Australia.

\section{Authors' contributions}

JW undertook initial analysis of interview transcripts, and HCP and HCT participated in discussions about analyses of the study and the reporting JW, HPC and HCT drafted the manuscript. HCT developed the health-mentor training. MN, AR, JS, PT, EHW and RWB were involved in all aspects of the study. All authors read and approved the final version of the manuscript.

Received: 14 March 2012 Accepted: 13 June 2012

Published: 13 June 2012

\section{References}

1. Lopez AD, Shibuya K, Rao C, Mathers CD, Hansell AL, Held LS, Schmid V, Buist S: Chronic obstructive pulmonary disease: current burden and future projections. Eur Respir J 2006, 27(2):397-412.

2. Knox SA, Harrison CM, Britt HC, Henderson JV: Estimating prevalence of common chronic morbidities in Australia. Med J Aust 2008, 189(2):66-70.

3. Charles J, Britt H, Fahridin S: COPD. Aust Fam Physician 2010, 39(3):93.

4. Walters JA, Walters EH, Nelson M, Robinson A, Scott J, Turner P, Wood-Baker $\mathrm{R}$ : Factors associated with misdiagnosis of COPD in primary care. Prim Care Respir J 2011, 20(4):396-402.

5. Walters JA, Hansen E, Walters EH, Wood Baker R: Under-diagnosis of Chronic obstructive Pulmonary Disease: a qualitative study in primary care. Respir Med 2008, 102(5):738-743.

6. Walters JA, Hansen E, Mudge P, Johns DP, Walters EH, Wood-Baker R: Barriers to the use of spirometry in general practice. Aust Fam Physician 2005, 34(3):201-203.

7. van Manen JG, Bindels PJE, Dekker FW, Bottema BJAM, van der Zee JS, ljzermans CJ, Schade E: The influence of COPD on health-related quality of life independent of the influence of comorbidity. J Clin Epidemio/ 2003, 56(12):1177-1184.

8. Access Economics Pty Limited: Economic impact of COPD and cost effective solutions.: The Australian Lung Foundation; 2008.

9. Wagner $\mathrm{EH}$ : Chronic disease management: what will it take to improve care for chronic illness? Effect Clin Pract 1998, 1(1):2-4.

10. Bourbeau J, Nault D, Dang-Tan T: Self-management and behaviour modification in COPD. Patient Educ Counsel 2004, 52(3):271-277. 
11. Barlow J, Wright C, Sheasby J, Turner A, Hainsworth J: Self-management approaches for people with chronic conditions: a review. Patient Educ Counsel 2002, 48(2):177-187.

12. McKenzie DK, Frith PA, Burdon JG, Town Gl: The COPDX Plan: Australian and New Zealand Guidelines for the management of Chronic Obstructive Pulmonary Disease. Med J Aust 2003, 178(Suppl):S7-S39.

13. Chen $K-H$, Chen M-L, Lee S, Cho H-Y, Weng L-C: Self-management behaviours for patients with chronic obstructive pulmonary disease: a qualitative study. J Adv Nurs 2008, 64(6):595-604.

14. Jones RC, Hyland ME, Hanney K, Erwin J: A qualitative study of compliance with medication and lifestyle modification in Chronic Obstructive Pulmonary Disease (COPD). Prim Care Respir J 2004, 13(3):149-154.

15. Seemungal TAR, Donaldson GC, Paul EA, Bestall JC, Jeffries DJ, Wedzicha JA: Effect of exacerbation on quality of life in patients with chronic obstructive pulmonary disease. Am J Respir Crit Care Med 1998, 157:1418-1422.

16. Hernandez $P$, Balter $M$, Bourbeau J, Hodder R: Living with chronic obstructive pulmonary disease: A survey of patients' knowledge and attitudes. Respir Med 2009, 103(7):1004-1012.

17. Hansen E, Walters JAE, Wood-Baker R: Explaining chronic obstructive pulmonary disease (COPD): perceptions of the role played by smoking. Sociol Health Illness 2007, 29(5):1-20.

18. Australian Bureau of Statistics: 2004-2005 National Health Survey. Canberra: Commonwealth of Australia; 2006

19. Commonwealth of Australia: Australia: The Healthiest Country by 2020 National Preventative Health Strategy - the roadmap for action.; 2009.

20. Bourbeau J: The role of collaborative self-management in pulmonary rehabilitation. Semin Respir Crit Care Med 2009, 30(6):700-707.

21. Bourbeau J, Julien M, Maltais F, Rouleau M, Beaupre A, Begin R, Renzi $P$, Nault D, Borycki E, Schwartzman K, et al: Reduction of Hospital Utilization in Patients With Chronic Obstructive Pulmonary Disease: A Disease-Specific Self-management Intervention. Arch Intern Med 2003, 163(5):585-591.

22. Jansink R, Braspenning J, van der Weijden T, Elwyn G, Grol R: Primary care nurses struggle with lifestyle counseling in diabetes care: a qualitative analysis. BMC Fam Pract 2010, 11:41.

23. Eakin EG, Brown WJ, Marshall AL, Mummery K, Larsen E: Physical activity promotion in primary care: bridging the gap between research and practice. Am J Prev Med 2004, 27(4):297-303.

24. Vale MJ, Jelinek MV, Best JD, Dart AM, Grigg LE, Hare DL, Ho BP, Newman RW, McNeil JJ: Coaching patients On Achieving Cardiovascular Health (COACH): a multicenter randomized trial in patients with coronary heart disease. Arch Intern Med 2003, 163(22):2775-2783.

25. Jowsey T, Jeon YH, Dugdale P, Glasgow NJ, Kljakovic M, Usherwood T: Challenges for co-morbid chronic illness care and policy in Australia: a qualitative study. Aust New Zeal Health Pol 2009, 6:22.

26. SNAP: a population health guide to behavioural risk factors in general practice. http://www.racgp.org.au/guidelines/greenbook.

27. Medical Research Council: Respiratory symptoms questionnaire. London: 1976.

28. Hansen E: Analysing qualitative data. In Successful qualitative health research: a practical introduction. NSW, Australia: Allen and Unwin; 2006:137-160.

29. Kitto SC, Chesters J, Grbich C: Quality in qualitative research. Med J Aust 2008, 188(4):243-246

30. Williams K, Prevost AT, Griffin S, Hardeman W, Hollingworth W, Spiegelhalter $D$, Sutton S, Ekelund U, Wareham N, Kinmonth AL: The ProActive trial protocol - a randomised controlled trial of the efficacy of a family-based, domiciliary intervention programme to increase physical activity among individuals at high risk of diabetes. BMC Publ Health 2004, 4(1):48.

31. Eakin E, Reeves M, Lawler S, Graves N, Oldenburg B, Del Mar C, Wilke K, Winkler E, Barnett A: Telephone Counseling for Physical Activity and Diet in Primary Care Patients. Am J Prev Med 2009, 36(2):142-149.

32. Laws R, Kemp L, Harris M, Davies G, Williams A, Eames-Brown R: An exploration of how clinician attitudes and beliefs influence the implementation of lifestyle risk factor management in primary healthcare: a grounded theory study. Implement Sci 2009, 4(1):66

33. Shahab L, Jarvis MJ, Britton J, West R: Prevalence, diagnosis and relation to tobacco dependence of chronic obstructive pulmonary disease in a nationally representative population sample. Thorax 2006, 61(12):1043-1047.

34. Williams GC, McGregor HA, Sharp D, Levesque C, Kouides RW, Ryan RM, Deci EL: Testing a self-determination theory intervention for motivating tobacco cessation: Supporting autonomy and competence in a clinical trial. Health Psychol 2006, 25(1):91-101.
35. Pitta Fb, Takaki MY, Oliveira NIHd, Sant'Anna TJP, Fontana AD, Kovelis D, Camillo CA, Probst VS, Brunetto AF: Relationship between pulmonary function and physical activity in daily life in patients with COPD. Respir Med 2008, 102(8):1203-1207.

36. Belza B, Steele BG, Hunziker J, Lakshminaryan S, Holt L, Buchner DM: Correlates of Physical Activity in Chronic Obstructive Pulmonary Disease. Nurs Res 2001, 50(4):195-202

37. Garcia-Aymerich J, Lange $P$, Benet $M$, Schnohr $P$, Anto JM: Regular Physical Activity Modifies Smoking-related Lung Function Decline and Reduces Risk of Chronic Obstructive Pulmonary Disease: A Population-based Cohort Study. Am J Respir Crit Care Med 2007, 175(5):458-463.

38. Sheridan N, Kenealy T, Salmon E, Rea H, Raphael D, Schmidt-Busby J: Helplessness, self blame and faith may impact on self management in COPD: a qualitative study. Prim Care Respir J 2011. epub ahead of print.

39. Johnson VD: Promoting behavior change: making healthy choices in wellness and healing choices in illness-use of self-determination theory in nursing practice. Nurs Clin N Am 2007, 42(2):229-241.

doi:10.1186/1471-2296-13-55

Cite this article as: Walters et al:: Supporting health behaviour change in chronic obstructive pulmonary disease with telephone health-mentoring: insights from a qualitative study. BMC Family Practice 2012 13:55.

\section{Submit your next manuscript to BioMed Central and take full advantage of:}

- Convenient online submission

- Thorough peer review

- No space constraints or color figure charges

- Immediate publication on acceptance

- Inclusion in PubMed, CAS, Scopus and Google Scholar

- Research which is freely available for redistribution

Submit your manuscript at www.biomedcentral.com/submit
C Biomed Central 